\section{(2) OPEN ACCESS}

${ }^{1}$ Institute for Social Marketing, Faculty of Health Sciences and Sport, University of Stirling, Stirling, UK

Institute of Occupational Medicine, Edinburgh, UK ${ }^{3} \mathrm{MRC} / \mathrm{CSO}$ Social \& Public Health Sciences Unit, University of Glasgow, Glasgow, UK ${ }^{4}$ Institute of Biological Chemistry, Biophysics and Bioengineering, Heriot-Watt University, Edinburgh, UK

\section{Correspondence to} Dr Sean Semple, Institute for Social Marketing, Faculty of Health Sciences and Sport, University of Stirling, Stirling FK9 4LA, UK;

sean.semple@stir.ac.uk

Received 27 June 2018 Accepted 14 August 2018 Published Online First 29 August 2018

\title{
Assessing progress in protecting non-smokers from secondhand smoke
}

\author{
Sean Semple (1) , ${ }^{1}$ Will Mueller, ${ }^{2}$ Alastair H Leyland, ${ }^{3}$ Linsay Gray, ${ }_{1}{ }^{3}$ John W Cherrie ${ }^{2,4}$
}

\section{ABSTRACT \\ Objective To examine trends in population exposure to secondhand smoke (SHS) and consider two exposure metrics as appropriate targets for tobacco control policy- makers.}

Design Comparison of adult non-smokers' salivary cotinine data available from 11 Scottish Health Surveys between 1998 and 2016.

Methods The proportions of non-smoking adults who had measurable levels of cotinine in their saliva were calculated for the 11 time points. The geometric mean (GM) concentrations of cotinine levels were calculated using Tobit regression. Changes in both parameters were assessed for the whole period and also for the years since implementation of smoke-free legislation in Scotland in 2006.

Results Salivary cotinine expressed as a GM fell from $0.464 \mathrm{ng} / \mathrm{mL}(95 \% \mathrm{Cl} 0.444$ to $0.486 \mathrm{ng} / \mathrm{mL})$ in 1998 to $0.013 \mathrm{ng} / \mathrm{mL}(95 \% \mathrm{Cl} 0.009$ to $0.020 \mathrm{ng} / \mathrm{mL})$ in 2016 : a reduction of $97.2 \%$. The percentage of non-smoking adults who had no measurable cotinine in their saliva increased by nearly sixfold between 1998 (12.5\%, $95 \% \mathrm{Cl} 11.5 \%$ to $13.6 \%)$ and $2016(81.6 \%, 95 \% \mathrm{Cl}$ $78.6 \%$ to $84.6 \%$ ). Reductions in population exposure to SHS have continued even after smoke-free legislation in 2006.

Conclusions Scotland has witnessed a dramatic reduction in SHS exposure in the past two decades, but there are still nearly one in five non-smoking adults who have measurable exposure to SHS on any given day. Tobacco control strategies globally should consider the use of both the proportion of non-smoking adults with undetectable salivary cotinine and the GM as targets to encourage policies that achieve a smoke-free future.

\section{INTRODUCTION}

Globally, exposure to secondhand smoke (SHS) continues to be a major cause of mortality and ill health with recent estimates suggesting it accounts for nearly 600000 deaths and approaching 11 million disability-adjusted life years annually. ${ }^{1}$ One of the key principles of article 8 of WHO Framework Convention on Tobacco Control is that 'all people should be protected from exposure to tobacco smoke.'2

Smoke-free legislation has been introduced in many developed countries in the past decade with the focus on protecting workers and non-smokers from exposure to SHS in enclosed public spaces. ${ }^{3}$ This has been shown to be successful in reducing concentrations of SHS in many settings ${ }^{45}$ and to have consequent public health benefits. ${ }^{67}$ However, much less effort has been expended on reducing exposure to SHS in homes, and there is some evidence that practitioners and policy-makers feel that the 'SHS problem' has been addressed and solved. ${ }^{8}$

Scotland has a rich source of data on population exposure to SHS with the Scottish Health Survey taking place on 11 occasions between 1995 and 2016. This comprehensive nationwide survey captures data from across Scotland with sample sizes typically in the range of 4000-9000 adults. The 2015 Scottish Health Survey report ${ }^{9}$ presented summary details of salivary cotinine concentrations of all non-smoking adults who provided a valid saliva sample spanning surveys from 2003 to 2015. Using a value of $0.05 \mathrm{ng} / \mathrm{mL}$, representing one-half of the analytical method limit of detection (LOD $=0.1 \mathrm{ng}$ / $\mathrm{mL}$ ), for all samples that were below this LOD the report provided a geometric mean (GM) value for all non-smoking adults. There is considerable debate in the exposure science community about how to handle such highly skewed, left-censored data, particularly where the proportion of 'non-detects' becomes substantial. ${ }^{10}{ }^{11}$ However, substituting half the LOD for undetectable values is likely to result in positively biased estimates of average exposure.

Providing policy-makers and other stakeholders with reliable and understandable information on exposure is key to ensuring that appropriate measures are taken to protect populations from the harms caused by SHS. There is a need to understand how population exposure to SHS has changed over time in countries that are attempting to enter an 'endgame' phase for tobacco use. This paper describes analysis of salivary cotinine data from subsamples of the non-smoking adults collected in the Scottish Health Survey since 1998 (the 1995 survey collected serum cotinine). The analysis seeks to present two useful metrics of population exposure: the proportion of non-smokers with non-measurable cotinine and calculation of the population GM based on a statistical methodology that takes account of undetectable cotinine levels.

\section{METHODS}

Scottish Health Survey data from 1998 to 2016 were acquired from the UK Data Service. ${ }^{12}$ The Scottish Health Survey is designed as a nationally representative sample of the population living in households in Scotland-full details of sample selection and data collection methods are available in each annual report. Data were restricted to those who were aged 16 or above and had a valid cotinine sample with a measure below $12 \mathrm{ng} / \mathrm{mL}$, the cut-point for validated non-smoking adults $(\mathrm{n}=13563$; ranging from 630 non-smoking adults in 2015 to 3738 in 1998). ${ }^{13}$ The proportion of valid samples that was below $0.1 \mathrm{ng} / \mathrm{mL}$, the $\mathrm{LOD}$ 


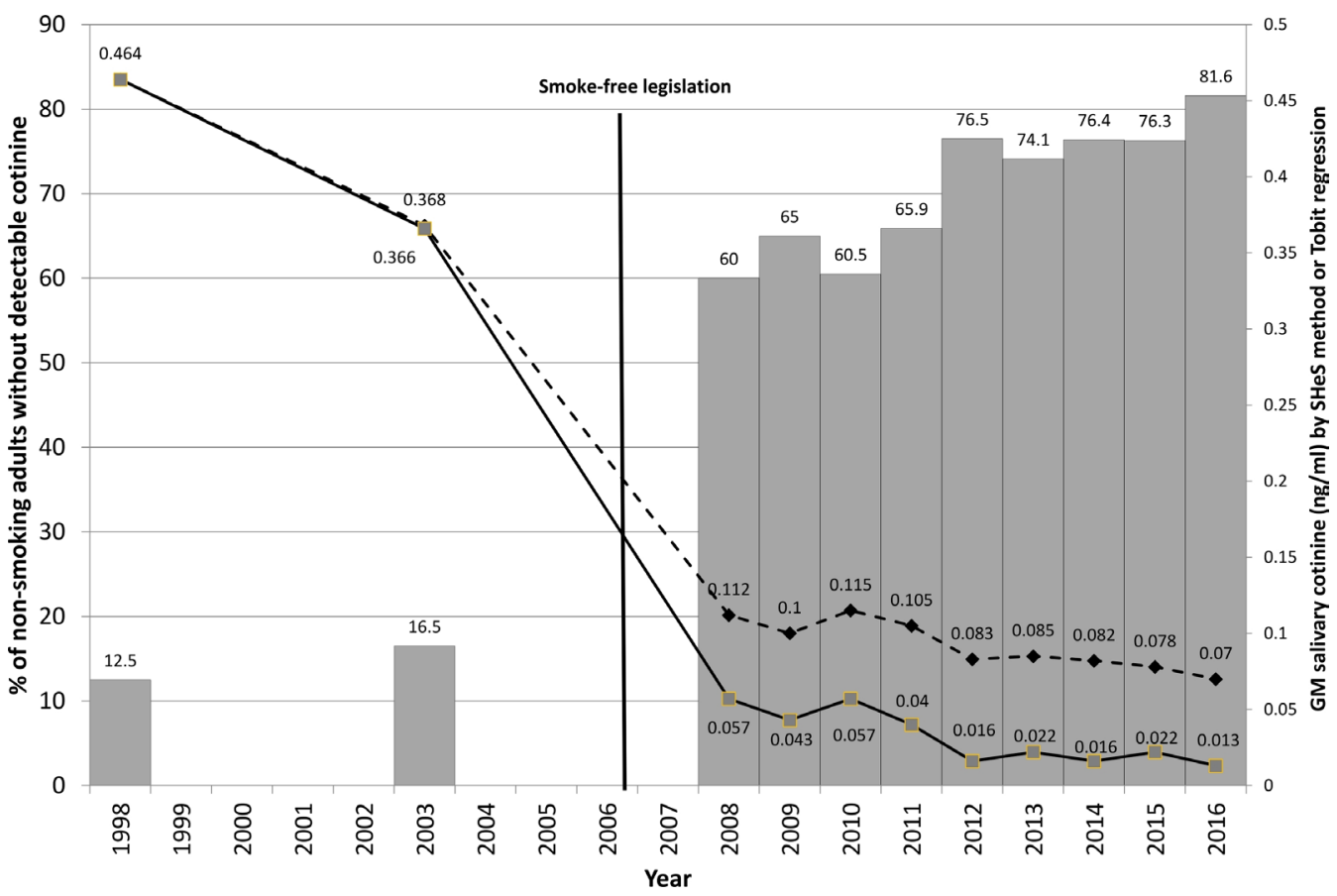

Figure 1 Scottish Health Survey salivary cotinine data from non-smoking adults 1998-2016. The bars represent the percentage of non-smoking adults with non-detectable cotinine, the dashed line shows the GM value calculated by the previous methodology using one-half the LOD; the solid line shows the GM value calculated using Tobit regression. GM, geometric mean; LOD, limit of detection; SHeS, Scottish Health Survey.

for salivary cotinine, was calculated for each time point. Tobit regression of log-transformed concentrations with the LOD as the lower limit was used to determine the GMand 95\% CI estimates. This method is recommended for use in datasets containing values below detection ${ }^{14}$ and has been used in other research on tobacco smoking. ${ }^{15}$ Data were extracted from the original SPSS V.19.0 files downloaded from the UK Data Service website and analysis was performed in Microsoft Excel and Stata V.13.1 (Stata Corporation). Change was calculated for the whole period 1998-2016. The trend during the period (2008-2016) after smoke-free legislation was implemented in Scotland in 2006 was assessed by fitting a linear best-fit line and determining the regression equation.

The method of sample collection has remained the same during the period reported here. The method of analysis of saliva samples used since the 2009 Scottish Health Survey is high-performance liquid chromatography coupled to tandem mass spectrometry with multiple reaction monitoring (LC-MS), replacing the gas chromatography nitrogen phosphorous detection method used in the 1998, 2003 and 2008 surveys. The sample preparation prior to LC-MS was liquid/liquid extraction. ${ }^{16}$ The LOD has remained the same during the period reported in this paper.

\section{RESULTS}

Figure 1 provides details of the salivary cotinine data for non-smoking adults in Scotland from the Scottish Health Surveys between 1998 and 2016. The percentage of non-smoking adults who had no detectable cotinine in their saliva increased from $12.5 \%$ (95\% CI $11.5 \%$ to $13.6 \%$ ) in 1998 to $81.6 \%$ (95\% CI $78.6 \%$ to $84.6 \%$ ) in 2016 . This represents a more than sixfold increase in the proportion of non-smokers being protected from the harms associated with exposure to SHS. The population exposure expressed as a GM, determined from Tobit regression, also reduced substantially from $0.464 \mathrm{ng} / \mathrm{mL} \quad(95 \% \mathrm{CI}$ 0.444 to $0.486 \mathrm{ng} / \mathrm{mL}$ ) in 1998 to $0.013 \mathrm{ng} / \mathrm{mL}$ (95\% CI 0.009 to $0.020 \mathrm{ng} / \mathrm{mL}$ ) in 2016 : a reduction of $97.2 \%$. Tobit regression-based estimates were lower by around $0.05 \mathrm{ng} / \mathrm{mL}$ than those derived from the previous methodology in all the years following the introduction of smoke-free legislation in Scotland.

Most of this change occurred between 2003 and 2008 during the period when restrictions on smoking in enclosed public spaces, encompassing nearly all work and leisure settings, were introduced in Scotland in March 2006. When the analysis of change is restricted to data from the years 2008 to 2016 (after smoke-free legislation was implemented), the results show continued improvements in the proportion of adults without measurable cotinine (from $60.0 \%$ in 2008 to $81.6 \%$ in 2016) by $2.67 \%$ per annum $\left(\mathrm{R}^{2}=0.85\right)$. Similarly, the $\mathrm{GM}$ of salivary cotinine concentrations reduced from 0.057 (95\% CI 0.047 to 0.070 ) to $0.013(95 \%$ CI 0.009 to 0.020$) \mathrm{ng} / \mathrm{mL}$ over 2008 to 2016 , respectively, by $-0.006 \mathrm{ng} / \mathrm{mL}$ per annum $\left(\mathrm{R}^{2}=0.76\right)$.

\section{DISCUSSION AND CONCLUSIONS}

This paper highlights dramatic reductions in exposure of non-smoking adults to SHS in the Scottish population. National time-series data on population exposure to SHS are scarce, ${ }^{91718}$ but they can play a key role in helping us better understand the effects of tobacco policy interventions. Measures of central tendency such as the arithmetic mean, median and mode are not well suited to describing exposures in datasets where a considerable proportion of the values are below the LOD. The GM is commonly used to provide statistical information in these cases but as data with 0 values cannot be included, it is often necessary to substitute or impute values for samples that are <LOD. In the 2015 Scottish Health Survey, ${ }^{9}$ the GM salivary cotinine was reported as $0.09 \mathrm{ng}$ / $\mathrm{mL}$ but this value was based on over three-quarters of the sample providing saliva with cotinine $<\mathrm{LOD}$, and thus being assigned a value of $0.05 \mathrm{ng} / \mathrm{mL}$, on the basis of it being halfway between 0 and the LOD of $0.1 \mathrm{ng} / \mathrm{mL}$ in accordance with traditional practice. The use of Tobit Regression imputation methods described here could 
be further developed to take account of other exposure predictors such as living with a smoker, occupational exposure, type of home.

The two metrics presented here-the proportion of the non-smoking population that have measurable cotinine in their saliva and a valid measure of central tendency that takes account the increasing proportion of the population who have cotinine values below the level of detection-provide policy-makers with much clearer data. However, there is a high proportion of the cotinine samples below the LOD, and the estimated GM level is almost $1 / 10$ of the LOD. Efforts should be made to improve the chemical analytical techniques to increase the reliability of the quantitative measures of changes in the population exposure to SHS.

In 1998, just over 1 in every 10 non-smoking adults presented with no biochemical evidence of exposure to SHS, by 2016 that had risen to more than 8 in every 10 . Our results reflect similar findings from a large study in England on temporal changes in salivary cotinine levels in children: the proportion of children with no detectable cotinine rose from $14.3 \%$ in 1998 to $68.6 \%$ in $2012 .{ }^{17}$

Our data show that the proportion of non-smoking adults in Scotland with detectable cotinine has continued to fall for the past decade. Recent work on SHS in Scotland has focused almost exclusively on protecting children from SHS with a media campaign 'Take It Right Outside' running in 2014/2015, and a national target set to reduce children's exposure to SHS launched by the Scottish Government. ${ }^{19}$ It is possible that this drive to change smoking behaviour in home settings has led to consequent reductions in the proportion of adult non-smokers with no measurable cotinine concentrations in 2016.

Objective measures of SHS exposure using biomarkers are important but not available in all countries. Other indicators of tobacco control progress can include assessment of compliance with smoke-free legislation and measurements of air concentrations in hospitality and other venues-a toolkit for use in low-income and middle-income countries has been published. ${ }^{20}$ Markers such as the proportion of smoke-free homes tend to rely on self-report, and these can be influenced by attitudes and social norms. The Scottish Health Survey for 2012-2016 gathered self-report data from non-smoking adults about their perceived exposure to SHS in their own or other people's homes, at work, outside buildings, in cars/vans and in other public places. In each of the 2012, 2013 and 2014 surveys, 70\% of non-smokers said they had not been exposed to smoke in any of these places; rising to $74 \%$ in 2015 and was $73 \%$ in $2016 .{ }^{21}$ It is encouraging that these figures are broadly similar to the data presented here in terms of the proportion of non-smoking adults with no measurable salivary cotinine.

Our study did not analyse the sociodemographic patterning of salivary cotinine concentrations, but it is worth noting that the 2016 Scottish Health Survey reports a gradient in terms of self-reported exposure to SHS where 75\% of non-smoking adults living in the $20 \%$ most affluent areas reported no exposure to SHS compared with just $64 \%$ of those living in the $20 \%$ most deprived homes. $^{21}$

While observing the improvements achieved in Scotland and elsewhere, ${ }^{171822}$ it is important to note that the most recent results here indicate that nearly one-fifth of the non-smoking adult population in Scotland is exposed to SHS on any given day. The situation is likely to be similar in many countries where smoke-free measures are well developed and while much of this exposure takes place in home settings there is still considerable evidence that non-smokers are exposed in the workplace, cars and peripheral settings such as building entrances and outdoor areas of bars. ${ }^{21}$ Recent work has shown that those employed in the prison sector continue to be occupationally exposed to
$\mathrm{SHS}^{23}$ as are health and community care workers who enter smokers' homes to provide care. ${ }^{24}$ The 'SHS issue' is not yet 'solved': the public health community needs to continue their efforts and consider further measures to protect non-smokers from SHS. The use of objective measurements, such as salivary cotinine and appropriate targets for policy-makers should be encouraged as a route to develop interventions and tobacco control measures relating to SHS.

\section{What this paper adds}

- Exposure to secondhand smoke (SHS) evidenced by salivary cotinine in non-smoking adults in Scotland has fallen dramatically in the past two decades.

- Reductions in population exposure to SHS continued after introduction of smoke-free laws in 2006.

- The proportion of non-smoking adults with salivary cotinine at concentrations $<0.1 \mathrm{ng} / \mathrm{mL}$ provides a useful indicator of national progress towards article 8 of WHO Framework Convention on Tobacco Control.

Acknowledgements We are grateful to John Watson from ASH Scotland for his comments on an early draft.

Contributors SS conceived the study, identified the data, performed preliminary analysis and wrote the draft manuscript. WM assisted with the statistical analysis and contributed to drafting and finalising the manuscript. AHL, LG and JWC contributed to drafting and finalising the manuscript.

Funding This work was carried out as part of employment at the Universities of Stirling and Aberdeen (SS), Glasgow (AHL and LG) and Heriot Watt (JWC). LG and AHL receive core funding from the Medical Research Council (MC_UU_12017/13) and the Scottish Government Chief Scientist Office (SPHSU13).

Competing interests None declared.

Patient consent Not required.

Provenance and peer review Not commissioned; internally peer reviewed.

Open access This is an open access article distributed in accordance with the Creative Commons Attribution 4.0 Unported (CC BY 4.0) license, which permits others to copy, redistribute, remix, transform and build upon this work for any purpose, provided the original work is properly cited, a link to the licence is given, and indication of whether changes were made. See: https://creativecommons.org/ licenses/by/4.0/.

\section{ORCID iD}

Sean Semple http://orcid.org/0000-0002-0462-7295

\section{REFERENCES}

1 Oberg M, Jaakkola MS, Woodward A, et al. Worldwide burden of disease from exposure to second-hand smoke: a retrospective analysis of data from 192 countries. Lancet 2011;377:139-46.

2 World Health Organisation. Framework Convention on Tobacco Control. Geneva, Switzerland, 2005. http://www.who.int/tobacco/framework/WHO_FCTC_english.pdf. (accessed 18 Jun 2018)

3 Hoffman SJ, Tan C. Overview of systematic reviews on the health-related effects of government tobacco control policies. BMC Public Health 2015;15:744

4 Semple S, Creely KS, Naji A, et al. Secondhand smoke levels in Scottish pubs: the effect of smoke-free legislation. Tob Control 2007;16:127-32.

5 Ward M, Currie LM, Kabir Z, et al. The efficacy of different models of smoke-free laws in reducing exposure to second-hand smoke: a multi-country comparison. Health Policy 2013;110:207-13.

6 Mackay DF, Irfan MO, Haw S, et al. Meta-analysis of the effect of comprehensive smoke-free legislation on acute coronary events. Heart 2010;96:1525-30.

7 Faber T, Sheikh A, Been JV. Smoke-free legislation and its impact on paediatric respiratory health. Eur Respir J 2016;48:1814-5.

8 Ritchie DD, Amos A, Shaw A, et al. How do policy advisors and practitioners prioritise the protection of children from secondhand smoke exposure in a country with advanced tobacco control policy? Tob Control 2015;24:70-6.

9 Scottish Government. The ScottishHealth Survey. Edinburgh. ISBN 9781786524614 http://www.gov.scot/Resource/0050/00505798.pdf. (accessed 18 Jun 2018).

10 Ogden TL. Handling results below the level of detection. Ann Occup Hyg 2010;54:255-6. 
11 Huynh T, Ramachandran G, Banerjee S, et al. Comparison of methods for analyzing left-censored occupational exposure data. Ann Occup Hyg 2014;58:1126-42.

12 UK Data Service. https://www.ukdataservice.ac.uk/ [accessed 18 Jun 2018]

13 Martínez-Sánchez JM, Fu M, Ariza C, et al. [Optimal cut-point of salivary cotinine concentration to discriminate smoking status in the adult population in Barcelona]. Gac Sanit 2009;23:501-5.

14 Lubin JH, Colt JS, Camann D, et al. Epidemiologic evaluation of measurement data in the presence of detection limits. Environ Health Perspect 2004;112:1691-6.

15 Whitehead T, Metayer C, Ward MH, et al. Is house-dust nicotine a good surrogate for household smoking? Am J Epidemiol 2009;169:1113-23.

16 Bernert JT, Jacob P, Holiday DB, et al. Interlaboratory comparability of serum cotinine measurements at smoker and nonsmoker concentration levels: a round-robin study. Nicotine Tob Res 2009;11:1458-66.

17 Jarvis MJ, Feyerabend C. Recent trends in children's exposure to second-hand smoke in England: cotinine evidence from the Health Survey for England. Addiction 2015;110:1484-92.
18 Wei B, Bernert JT, Blount BC, et al. Temporal trends of secondhand smoke exposure: nonsmoking workers in the United States (NHANES 2001-2010). Environ Health Perspect 2016;124:1568-74.

19 News BBC. Campaign to cut children's smoke exposure. 2014 http://www.bbc.co.uk/ news/uk-scotland-scotland-politics-26732748 (accessed 22 Jul 2014).

20 Jackson-Morris A, Bleymann K, Lyall E, et al. Low-cost air quality monitoring methods to assess compliance with smoke-free regulations: a multi-center study in six low- and middle-income countries. Nicotine Tob Res 2016;18:1258-64.

21 Scottish Government. The 2016 Scottish Health Survey. Edinburgh. ISBN 9781788512763. http://www.gov.scot/Resource/0052/00525472.pdf. (accessed 18 Jun 2018).

22 Woodward A. Commentary on Jarvis \& Feyerabend (2015): A truly smoke-free upbringing, once rare, is now commonplace. Addiction 2015;110:1493-4.

23 Semple S, Sweeting $H$, Demou E, et al. Characterising the exposure of prison staff to second-hand tobacco smoke. Ann Work Expo Health 2017;61:809-21.

24 Angus $\mathrm{K}$, Semple S. Home health and community care workers' occupational exposure to second-hand smoke: A rapid literature review. Nicotine Tob Res. 